OPEN ACCESS

Edited by:

Gemma Caterina Maria Rossi, Fondazione Ospedale San Matteo

(IRCCS), Italy

Reviewed by:

Raghu R. Krishnamoorthy, University of North Texas Health

Science Center, United States Yasushi Kitaoka, St. Marianna University School of Medicine, Japan Huaizhou Wang,

Capital Medical University, China

${ }^{*}$ Correspondence: Alessandro Arrigo alessandro.arrigo@hotmail.com

Received: 25 July 2021 Accepted: 27 August 2021 Published: 06 October 2021

Citation: Arrigo A, Aragona E, Saladino A, Arrigo D, Fantaguzzi F, Battaglia Parodi $M$ and Bandello $F$ (2021) Cognitive Dysfunctions in

Glaucoma: An Overview of Morpho-Functional Mechanisms and the Impact on Higher-Order Visual Function.

Front. Aging Neurosci. 13:747050. doi: 10.3389/fnagi.2021.747050

\section{Cognitive Dysfunctions in Glaucoma: An Overview of Morpho-Functional Mechanisms and the Impact on Higher-Order Visual Function}

\author{
Alessandro Arrigo ${ }^{1 *}$, Emanuela Aragona ${ }^{1}$, Andrea Saladino ${ }^{1}$, Davide Arrigo ${ }^{2}$, \\ Federico Fantaguzzi ${ }^{1}$, Maurizio Battaglia Parodi ${ }^{1}$ and Francesco Bandello ${ }^{1}$ \\ ${ }^{1}$ Department of Ophthalmology, Scientific Institute San Raffaele Hospital, Milan, Italy, ${ }^{2}$ School of Medicine, University of \\ Messina, Messina, Italy
}

Background: Glaucoma is a chronic, vision-threatening disease, and a major cause of legal blindness. The current view is no longer limited to the progressive optic nerve injury, since growing evidence strongly support the interpretation of glaucoma as a complex neurodegenerative disease. However, the precise pathogenic mechanisms leading to the onset and progression of central nervous system (CNS) impairment, and the functional consequences of this damage, are still partially understood. The main aim of this review is to provide a complete and updated overview of the current knowledge regarding the CNS involvement in glaucoma, and the possible therapeutic perspectives.

Methods: We made a careful survey of the current literature reporting all the relevant findings related to the cognitive dysfunctions occurring in glaucoma, with specific remarks dedicated on the higher-order visual function impairment and the possible employment of neuroprotective agents.

Results: The current literature strongly support the interpretation of glaucoma as a multifaceted chronic neurodegenerative disease, widely affecting the CNS. The cognitive impairment may vary in terms of higher-order functions involvement and in the severity of the degeneration. Although several neuroprotective agents are currently available, the development of new molecules represents a major topic of investigation for future clinical trials.

Conclusions: Glaucoma earned the right to be fully considered a neurodegenerative disease. Glaucomatous patients may experience a heterogeneous set of visual and cognitive symptoms, progressively deteriorating the quality of life. Neuroprotection is nowadays a necessary therapeutic goal and a future promising way to preserve visual and cognitive functions, thus improving patients' quality of life.

Keywords: glaucoma, neurodegenerative disease, cognitive impairment, neurodegeneration, neuroinflammation, neuroprotection, OCT, OCTA 


\section{INTRODUCTION}

The term "glaucoma" refers to a group of optic neuropathies characterized by degeneration of retinal ganglion cells (RGCs) and their axons. Their damage lead to the progressive thinning of retinal nerve fibers layer (RNFL) and cupping of the optic nerve head $(\mathrm{ONH})$. Structural changes result in characteristic visual field (VF) alterations, up to complete blindness. Glaucoma is considered a leading cause of blindness worldwide and it is estimated that the number of affected people will increase to approximately 111.82 million in 2040 (Pascolini and Mariotti, 2012; Tham et al., 2014). The main cause of this is that life expectancy is growing, and age is one of the major risk factors for glaucoma (Pascolini and Mariotti, 2012; Tham et al., 2014). The prevalence of primary open-angle glaucoma (POAG), the most common form of glaucoma in the Caucasians, increases significantly with age and many patients develop POAG around 60 years old, reaching a remarkably high incidence (at least 7\%) in the Barbadian population (Wensor et al., 1998; Gordon et al., 2002; Leske et al., 2004; European Glaucoma Prevention Study (EGPS) Group, 2007). Ocular hypertension $(\mathrm{OHT})$ is an important risk factor in the development of glaucoma and in its progression (The AGIS Investigators, 2000; Gordon et al., 2002; Heijl et al., 2002). According to the mechanical theory of glaucoma, OHT is the result of a backward displacement of the lamina cribrosa, which in turn would damage the axons of RGCs, compressing them between its meshes. Whereas increased IOP is likely to explain the pathogenesis of optic nerve damage in certain types of glaucoma, this may not be true for some other forms. In particular, normal tension glaucoma (NTG), which afflicts approximately $15-25 \%$ of glaucomatous patients, is a clinical condition in which, despite pathologic cupping of the $\mathrm{ONH}$ and characteristic VF alterations, IOP is within the normal range (Collaborative Normal-Tension Glaucoma Study Group, 1998; Kim and Park, 2016; Mallick et al., 2016). A relevant proportion of patients is characterized by different patterns of progression; the estimated prevalence of fast-progressors is between $4-10 \%$, and this subtype of patients is characterized by high risk of visual disability (Chauhan et al., 2014; Kirwan et al., 2014; Jammal et al., 2021). To explain NTG-related damages, various non-IOP dependent pathogenetic mechanisms have been proposed, like chronic hypoxia and ischemia, increased intracranial pressure, neuronal glutamate-induced excitotoxicity, mitochondrial dysfunction, oxidative stress, and autoimmunity (Hayreh, 1985; Flammer, 1994; Morgan et al., 1995, 1998, 2002; Romano et al., 1995, 1999; Dreyer et al., 1996; Tezel et al., 1998, 1999; Osborne et al., 2001; Flammer et al., 2002; Gherghel et al., 2005; Grieshaber and Flammer, 2005; Abu-Amero et al., 2006; Grus et al., 2006; Salt and Cordeiro, 2006; Ju et al., 2007; Berdahl et al., 2008a,b; Ren et al., 2010, 2011; Jonas, 2011; Chrysostomou et al., 2013; Siaudvytyte et al., 2014, 2015). Taking together all these factors, a more comprehensive view of glaucoma should be considered, assuming neurodegeneration as a key component of glaucoma pathogenesis. Indeed, many of the above-mentioned mechanisms have been proposed to explain the pathogenesis of neurodegenerative diseases of the central nervous system (CNS). Chronic hypoxia and ischemia account for the development of vascular dementia, which is the second most common cause of irreversible cognitive dysfunction after Alzheimer disease (AD). Excitotoxicity phenomena have been implicated in post-stroke cellular damage and in certain neurodegenerative diseases such as Huntington's disease, amyotrophic lateral sclerosis (ALS), Parkinson's disease (PD), and AD (Szatkowski and Attwell, 1994; Rego and Oliveira, 2003). In addition, glaucoma shares some characteristics with neurodegenerative diseases: increased incidence with age, insidious onset, progressive deterioration, and, frequently, a recognized genetic predisposition. This latter is characterized by the involvement of several genes, including myocilin, cytochrome P450 B1 and optineurin (Park et al., 2007; Kumar et al., 2016, 2017). In this complex scenario, this review would explore the clinical similarities between neurodegenerative disorders and glaucoma, the features that seem consistent with neurodegenerative mechanisms characterizing the pathogenesis of glaucoma, and the CNS changes occurring in glaucoma.

\section{METHODS}

We searched all English language and human subject articles using keywords search of MEDLINE library. The keywords included the following: glaucoma, open angle glaucoma, normotensive glaucoma, OHT, neurodegeneration, neurodegenerative disease, neuroplasticity, neuroretina, optic nerve, $\mathrm{ONH}$, multimodal imaging, neuroimaging. All the references were carefully examined by two expert researchers (AA,EA) which collected and ordered all the relevant information, considering the main topic of this review as expressed in the manuscript title.

\section{MULTIMODAL IMAGING OF THE EYE APPLIED ON GLAUCOMA}

Multimodal imaging radically changed the diagnostic approach to posterior segment diseases. This is intended as a set of non-invasive tools assessing different morphological characteristics of the retina and the ONH. Fundus autofluorescence is able to detect the light absorption and emission properties of retinal fluorophores characterizing normal retina and pathological conditions (SchmitzValckenberg et al., 2008). Although representing a very important diagnostic tool in retinal diseases, its usage in glaucoma setting is still limited. However, some studies describing $\mathrm{ONH}$ autofluorescence changes occurring in glaucoma and the correlation with retinal fibers thinning suggest the utility of this multimodal imaging technique also in glaucoma setting (Viestenz et al., 2006; Reznicek et al., 2013). Optical coherence tomography (OCT) is a laser-based technique able to investigate reflectivity properties of retinal structures and to provide histology-like information (Thomas and Duguid, 2004). It's role in glaucoma setting is fundamental since it allowed to quantitatively detect ganglion cells layer (GCL) and RNFL alterations and to progressively monitor their evolution 
with very high accuracy (Leung et al., 2010; Langenegger et al., 2011; Tong et al., 2021). It represents an extremely sensitive, reliable, and reproducible diagnostic approach, and nowadays is of very high utility in the diagnosis and management of glaucoma (Figure 1; Leung et al., 2010; Tong et al., 2021). A recent evolution of OCT is represented by OCT angiography (OCTA), which is able to detect motion signal coming from erythrocytes and to reconstruct intraretinal capillaries (Spaide et al., 2018). If OCTA is of great utility in other retinal diseases, its role in glaucoma setting is still limited. Several previous papers tried to detect early vascular biomarkers of glaucoma onset and progression, demonstrating significant correlations between alterations of the deep capillary plexus and the radial peripapillary capillaries with structural OCT changes and VF damages, thus reinforcing the role of OCTA employment in glaucoma diagnostic workup (Lee et al., 2016; Spaide et al., 2018; Van Melkebeke et al., 2018; Bojikian et al., 2019; Li et al., 2021). A recent report of the American Academy of Ophthalmology highlighted how the quantitative evaluation of vessel density alterations through OCTA may complement
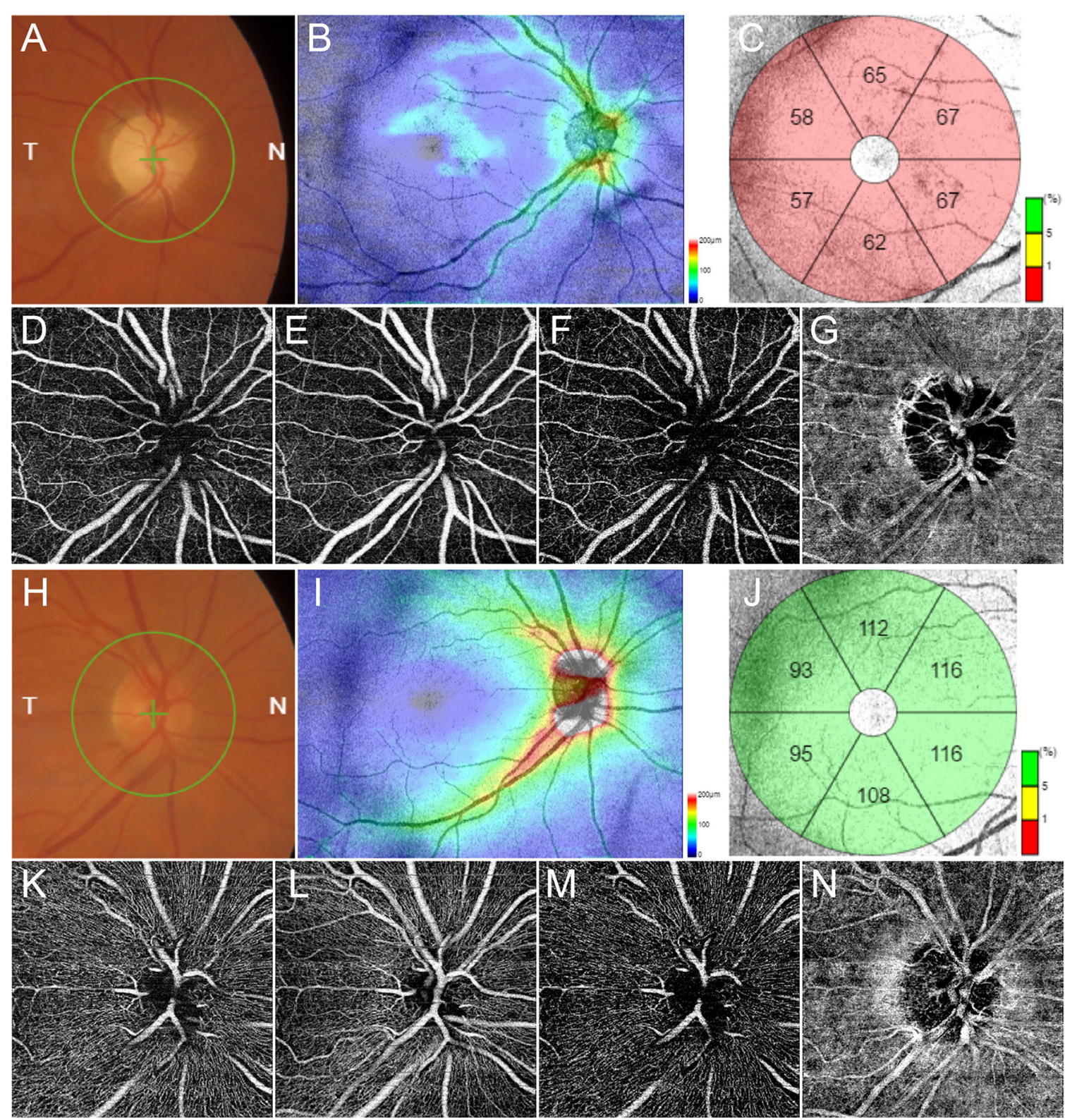

FIGURE 1 | Multimodal imaging in glaucoma. Fundus examination reveals an evident excavation of the optic disc (A). Structural optical coherence tomography $(\mathrm{OCT})$ detects a remarkable thinning of retinal nerve fibers layer (RNFL) (B) and ganglion cells layer (GCL) (C). OCT angiography (OCTA) shows rarefied radial peripapillary capillary and deep capillary plexa (D,F respectively), and preserved superficial capillary plexus and choriocapillaris (E,G respectively). Multimodal imaging findings in a normal control is shown in $(\mathbf{H}-\mathbf{N})$, respectively. 
TABLE 1 | Main visual system alterations in neurodegenerative diseases.

\begin{tabular}{|c|c|}
\hline Alzheimer Disease & Parkinson Disease \\
\hline Visual acuity reduction & Visual acuity reduction \\
\hline Visual field alterations & Visual field alterations \\
\hline Color discrimination impairment & Color discrimination impairment \\
\hline Electrophysiology alterations & Eye movements function deficits \\
\hline Contrast and temporal discrimination impairment & Pupil function and reactivity decreases \\
\hline Visual and visuo-motor tasks alterations & Electrophysiology alterations \\
\hline Visual hallucinations & Contrast and temporal discrimination impairment \\
\hline Posterior pole morpho-functional alterations & Visual and visuo-motor tasks alterations \\
\hline Balint's syndrome (simultanagnosia + ocular motor apraxia + optic ataxia) & Visual hallucinations \\
\hline Corneal nerves alterations & Corneal nerves alterations \\
\hline Retinal and optic nerve morpho-functional alterations & Retinal and optic nerve morpho-functional alterations \\
\hline Intracranial visual system morpho-functional changes & Intracranial visual system morpho-functional changes \\
\hline
\end{tabular}

the other diagnostic modalities in glaucoma setting (Figure 1; WuDunn et al., 2021).

\section{OPHTHALMIC MANIFESTATIONS OF NEURODEGENERATIVE DISEASES}

The eye is often defined as a "window into the brain," for the big amount of neuroanatomical and vascular information achievable by means of non-invasive diagnostic modalities. Several ocular and visual manifestations have been previously described as complained by patients affected by mild cognitive impairment (MCI) and $\mathrm{AD}$, including extraocular muscles impairment, pupillary defects, RNFL and GCL thinning and visual alterations (for example contrast sensitivity, color vision, VF, visuomotor coordination; Hinton et al., 1986; Trick et al., 1995; Lakshminarayanan et al., 1996; Rizzo et al., 2000; Gilmore et al., 2006; Scinto, 2007; Garbutt et al., 2008; Kavcic et al., 2011; Lee and Pai, 2012; Risacher et al., 2013; Coppola et al., 2015; Liu et al., 2015). In this context, the eye is not a passive viewer of the neurodegenerative cascade occurring in the CNS but is directly involved in MCI/AD pathogenesis. Several studies reported wide accumulations of amyloid-beta precursor protein and $\beta$-amyloid within the inner retinal layers (Ning et al., 2008; Koronyo et al., 2012). Furthermore, OCTA was able to detect statistically significant alterations of the intraretinal vascular network in AD patients (van de Kreeke et al., 2020; Wang et al., 2021). The level of evidence regarding the role of retinal diagnostic tools for the early detection of $\mathrm{AD}$ is growing, thus promoting the eye as an early biomarker of neurodegenerative disorders (Lim et al., 2016; CerqueraJaramillo et al., 2018; Colligris et al., 2018). Similar considerations may be done also considering other neurodegenerative diseases, first of all PD. Although it was mainly considered as a motor disorder, the current point of view regarding PD is changing, nowadays considering this as a complex neurodegenerative disease (Armstrong, 2008). Visual manifestations in PD include a widespread set of alterations involving almost all eye and visual system components (Armstrong, 2011). Interestingly, morpho-functional changes and visual dysfunctions may occur also many years before the onset of motor disorders, both involving the eye and the intracranial visual system, thus strongly suggesting the adoption of ocular findings as early biomarkers of PD onset (Armstrong, 2011; Arrigo et al., 2017a,b, 2018; Guo et al., 2018; Cuerca, 2019; Sung et al., 2019). All these findings provide the basis to explain the wide range of visual alterations complained by patients affected by neurodegenerative diseases. In Table $\mathbf{1}$ the main visual dysfunction described in two of the most important and representative neurodegenerative diseases, namely $\mathrm{AD}$ and $\mathrm{PD}$, are shown. If in this section we described the eye as a structure damaged by pathogenic sources having their primary site in the brain, it should be considered that primary degeneration of ocular structures may induce remarkable changes of the CNS, thus placing the basis for assessing that the neurodegeneration in the eye may somehow have an impact on the neurodegeneration in the brain. The CNS changes occurring as the consequence of primary eye disorders are discussed in the next sections.

\section{NEURODEGENERATIVE MANIFESTATIONS IN OPHTHALMIC DISEASES}

The other side of the coin is the involvement of the CNS in ophthalmic diseases, representing a topic of growing interest for the clinical and scientific communities (Prins et al., 2016). Indeed, posterior segment disorders can induce neurodegenerative and neuroplasticity phenomena within the brain, towards anterograde and retrograde transsynaptic mechanisms. Age-related macular degeneration is associated with deep degenerative changes of the intracranial visual pathways, functional impairment of visual and visuomotor tasks and CNS connectivity network modifications induced by neuroplasticity phenomena (Lešták et al., 2013; Rosengarth et al., 2013; Hernowo et al., 2014). Similar changes may occur also in inherited retinal dystrophies, where white matter network changes and cortical remapping have been described (Olivo et al., 2015; Ferreira et al., 2016; Rita Machado et al., 2017). If visual system changes occur in the first stages to try to compensate the progressive visual degeneration, the later stages of retinal diseases are characterized by extensive morpho-functional impairment also of the intracranial visual system (Nuzzi et al., 2020). Although still poorly investigated, the profound interconnection between the eye and CNS may have extremely 
important implications for a deeper understanding of visual processing mechanisms and for ocular and CNS diseases.

\section{GLAUCOMA AS A NEURODEGENERATIVE DISEASE}

The eye and the brain are strictly interconnected through the optic nerve and even growing evidence support the existence of a strong morpho-functional interconnection between these two compartments, allowing to share common pathogenic neurodegenerative pathways and manifestations. The most used models to assess the similarities between eye and brain neurodegeneration are glaucoma and AD. First of all, these two diseases are characterized by the similar retinal sites of damage, namely GCL and RNFL (Blanks et al., 1996a,b). Ganglion cells loss is mainly caused by increased oxidative and metabolic distress, neuroinflammation-mediated damage, and increased glial cells reactivity (McKinnon, 2012; Sivak, 2013; Jindal, 2015; Wei et al., 2019; Volkert and Crowley, 2020).

In this intricated scenario, glaucoma can be fully considered as a complex neurodegenerative disease. Indeed, the pathogenic features characterizing the progressive morpho-functional disruption of the neuroretinal structures and the patterns of involvement of the CNS in glaucoma share many common characteristics with other neurodegenerative disorders. A key molecular mechanism occurring in glaucoma is the neuroinflammation, a complex cascade of multifactorial events leading to the damage of neuroretinal structures (McKinnon, 2012; Wei et al., 2019; Jiang et al., 2020; Quaranta et al., 2021). Likely AD, glaucomatous damage is promoted by the activation of tumor necrosis factor-alpha and complement system pathways (Stasi et al., 2006; Tezel, 2008). Several autoantibodies of neuroinflammation and neurodegeneration have been found highly present in glaucomatous patients, with different patterns of expression between POAG and NTG (Vu et al., 2019). In addition, other circulating biomarkers associated with neurotrophy, neuroprotection and oxidative stress have been found altered in glaucoma, including serum homocysteine, vitamin B12, folic acid and endothelin-1 (ET-1; Cumurcu et al., 2006; Turgut et al., 2010; Türkcü et al., 2013; López-Riquelme et al., 2015). Another remarkable similarity between glaucoma and $\mathrm{AD}$ is represented by the presence of amyloid precursor protein accumulations in glaucomatous eyes (McKinnon et al., 2002).

Amyloid- $\beta$ protein and its precursor are a major pathogenic source of damage, turning out to be at the center of several pathogenic cascades leading to the activation and promotion of neurodegeneration. The role of amyloid- $\beta$ in the retina is still unknown, although previous authors hypothesized an antimicrobial activity, similarly to what found within the CNS (Wostyn et al., 2015; Kumar et al., 2016; Naaman et al., 2020). On the other side, amyloid precursor protein is known to exert several neuroprotective activities, including the support to synaptogenesis and the promotion of neuronal development and survival (Jessen et al., 2015). This is true when amyloid- $\beta$ and amyloid precursor protein maintain monomeric configuration. However, it has been described the spontaneous aggregation of amyloid- $\beta$ into dimers, trimers, and oligomers; the insoluble form of amyloid- $\beta$ oligomers lead to the formation of protofibrils, fibrils, and insoluble amyloid plaques which are toxic for retinal neurons, activating several pathologic cascades similarly to what happen within the brain in $\mathrm{AD}$ (Naaman et al., 2020). Furthermore, amyloid precursor protein physiologically interacts with other molecules, including integrins and receptor tyrosine kinase; the impairment of this metabolic network was associated with tau-related excitotoxicity causing synaptic and axonal failure.

In glaucoma, a possible pathogenic hypothesis of amyloid- $\beta$ accumulation has been based on the dysfunction of the retinal glymphatic system (Wostyn et al., 2015). Indeed, the retina as well as the brain have no lymphatic vessels; for this reason, glial cells may work as scavenger elements, towards the aquaporins system, to allow the drainage of fluids and molecules (Jessen et al., 2015). The glymphatic system involvement in glaucoma might be based on the impaired outflow and stasis caused by changes of the pressure barrier across the lamina cribrosa. This latter is the result of a delicate balance of the intraocular and the intracranial pressures; an increased IOP or a decreased intracranial pressure may be the cause of the glymphatic system disruption (Wostyn et al., 2016; Wang et al., 2020; Wang and Mao, 2021).

Several evidences described other interesting molecular mechanisms significantly associated with the onset and progression of glaucomatous damage, including the disbalance of neurotrophic factors production, the reactive activation of glial cells, increased oxidative stress, dysregulation of the immune system, and energetic demand caused by mitochondrial dysfunction (Tezel and Wax, 2000; Tezel, 2006, 2021; Ju et al., 2009; Baudouin et al., 2021). In this context, increasing IOP values may act as a trigger for the onset of these pathogenic mechanisms, although these may independently occur, like in NTG (Munemasa and Kitaoka, 2013). Even growing studies are defining a multifactorial pathogenic scenario leading to the onset and progression of NTG, where several mechanisms including vascular dysregulation, mainly caused by ET-1dependent endothelial dysfunction (Moore et al., 2008), glial cells reactivity, leading to neuroinflammatory and oxidative distresses (Tezel and Wax, 2004; Mozaffarieh and Flammer, 2013), impairment of exchanges towards the lamina cribrosa (Tezel and Wax, 2004; Rao et al., 2007, 2008), and bloodbrain barrier disruption (Hofman et al., 2001; Grieshaber and Flammer, 2007). Other demonstrated neurotrophic deprivations regarded the reduced production and release of neurotrophins and brain-derived neurotrophic factor (Vrabec and Levin, 2007). These molecules are mainly released by Muller cells and are fundamental for neuronal cell survival (Vrabec and Levin, 2007). The involvement of Muller cells and other glial cytotypes resulted extremely important in the pathogenesis of glaucoma, leading to the progressive loss of retinal and optic nerve homeostasis, promoting neuroinflammation and neurodegeneration processes (Seki et al., 2005; Vrabec and Levin, 2007; Seitz et al., 2013; Chong and Martin, 2015). It is worth of notice that all these mechanisms are far from the pathogenic cascade which can be induced by the mere IOP value increases. All the main mechanisms characterizing neurodegeneration 


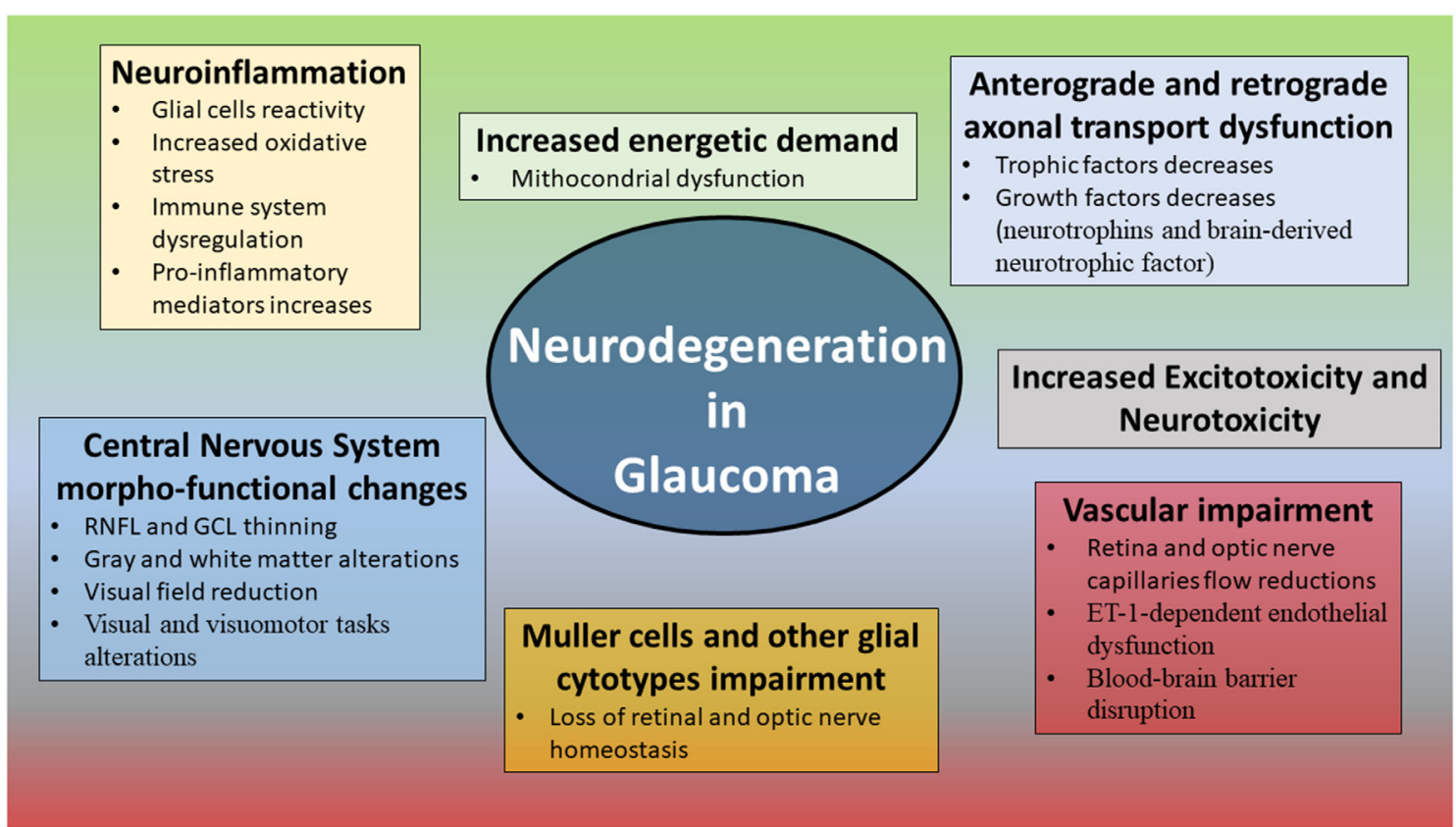

FIGURE 2 | Main alterations associated with neurodegenerative mechanisms in glaucoma.

in glaucoma are shown in Figure 2. In addition to all these factors making the neurodegenerative pathogenesis of glaucoma extremely complex, growing findings add a further cause of damage, represented by the impairment of the homeostatic brain and eye fluid balance. Indeed, decreased ocular and brain blood flows, cerebrospinal fluid disbalances, higher vascular resistance and diffuse cerebral hypoperfusion/ischemic changes have been described in glaucoma patients (Harris et al., 2003; Heringa et al., 2013). This chronic sufferance is not limited to the retina and the $\mathrm{ONH}$.

Indeed, what is of great interest is the number of changes and damages occurring at the level of the CNS. Magnetic resonance imaging (MRI) techniques described widespread modifications of the white matter tissue and the brain connectivity in patients affected by glaucoma, with strong correlations with RNFL/GCL impairment and VF alterations (Garaci et al., 2009; El-Rafei et al., 2013; Omodaka et al., 2014; Zhao et al., 2021). Similarly, several gray matter thinning of the visual cortex have been also described (Zhang et al., 2015; Zhou et al., 2017; Giorgio et al., 2018). Gray matter thinning involved also other brain regions over than the occipital cortex, including lingual gyrus, calcarine gyrus, postcentral gyrus, superior frontal gyrus, inferior frontal gyrus, rolandic operculum, cerebellar cortex, and hippocampus (Li et al., 2012, 2020; Frezzotti et al., 2014). On the other side, some other gray matter regions associated with visual processing turned out to be thicker in patients with glaucoma, including middle temporal gyrus, inferior parietal gyrus, angular gyrus, midbrain, brainstem, frontal gyrus, cerebellar vermis and thalamus (Jiang et al., 2017; Giorgio et al., 2018; Kasi et al., 2019). The wide involvement of extra-occipital regions may justify previous findings reporting significant alterations of white matter connections involved in visual and visuomotor tasks, and in high order functions, including the inferior frontooccipital fasciculus, the longitudinal and the inferior frontal fasciculi, putamen, caudate nucleus, anterior and posterior thalamic radiations and anterior and posterior limbs of the internal capsule (Zikou et al., 2012; Williams et al., 2013). Although the whole CNS alterations significantly correlated with the stage of glaucoma and disease's severity (Wang et al., 2021), many studies highlighted how gray and white matter extensive changes may be detected already at early stages of glaucomatous disease ( $\mathrm{Yu}$ et al., 2013; Frezzotti et al., 2016; Kasi et al., 2019) thus supporting the hypothesis that the CNS involvement is not only a secondary phenomenon related with optic nerve damage, but it may represent the result of an active cascade of pathological mechanisms evolving independently from the optic nerve degeneration. Taking together all the above described visual and non-visual brain connectivity alterations, it may be assumed that glaucomatous patients may suffer from brain processing dysfunctions localized at different levels, including visual and visuomotor tasks, memory and emotion, working memory and attention, default mode network and other multimodal brain functions (Zhang et al., 2016; Wang et al., 2017; Nuzzi et al., 2018; Giorgio et al., 2020).

\section{COGNITIVE IMPAIRMENT IN GLAUCOMA}

Cognitive impairment is a relatively novel concept described in glaucoma, which is gaining increased attention and importance. It represents a progressive decline of memory and multimodal high order brain functions, which is usually categorized, accordingly with the gravity of the cognitive deterioration, 
as MCI or dementia (Petersen, 2011; Jongsiriyanyong and Limpawattana, 2018). An increasing body of literature reported high frequency of cognitive impairment in patients affected by glaucoma than in normal controls (Harrabi et al., 2015; Su et al., 2016; Maurano et al., 2018; Varin et al., 2020). On the other side, patients with $\mathrm{AD}$ and dementia had an increased risk of glaucoma onset (Xu et al., 2019; Vidal et al., 2020). The link between these two apparently different conditions is further reinforced by the common finding of RNFL/GCL thinning and visual gray and white matters morpho-functional impairments (Iseri et al., 2006; Tamura et al., 2006; Ascaso et al., 2014; Jones-Odeh and Hammond, 2015). The relationship between retinal and CNS alterations is strong and support the role of OCT-based technology for the early diagnosis of cognitive dysfunctions and neurodegenerative diseases (Biscetti et al., 2021). A well-known glaucoma-related finding is the thinning of the lamina cribrosa, a complex tissue surrounding the $\mathrm{ONH}$ and providing structural and functional supports to the ganglion cells. Interestingly, lamina cribrosa thinning was found significantly associated with worse global cognitive function [measured by Mini-Mental State Exam (MMSE) score], independently from the severity of glaucoma (Lee et al., 2020). The cognitive impairment in glaucoma, measured by means of different cognitive assessment tests, opens new management issues with respect to the reliability of VF examination; many studies showed a significant relationship between neurocognitive decline and VF variability, placing a solid basis for a remarkable structure-function relationship mismatch which may interfere with the proper management of glaucomatous patients (DinizFilho et al., 2017; Honjo et al., 2017; Raman et al., 2019). Indeed, decreased VF test reliability can delay the detection of true progression of the disease, potentially resulting in irreversible visual function loss. Conversely, false VF worsening, when no true changes occur, may lead to unnecessary treatment changes with potential negative effects for patients. On the other hand, visual function decrease may contribute to cognitive deterioration, because of leading patients to lower daily activity levels and progressive loss of self-sufficiency, especially in older ages (Bassuk et al., 1999; Wilson et al., 2002). As above described, the involvement of the CNS and the impairment of cognitive functions in glaucoma is ruled by extensive changes of functional connectivity networks, with increased phenomena of neuroplasticity and neurodegeneration. Because of its relatively recent discovery, few studies have been conducted focusing on cognitive dysfunctions in glaucoma. However, if considering the importance of the visual function in cognitive tasks, this research field should be object of further investigations in glaucoma. Just to provide an example, it was demonstrated that sensory functions impairments have a direct role in cognitive aging, since good sensory functions, with particular regard to visual task, were found strongly predictive of the cognitive performance (Glass, 2007). Interestingly, each visual function has a different impact on cognitive impairment, with contrast sensitivity seeming to have the strongest relationship with cognitive tests scores (Varadaraj et al., 2021). It is worth of notice that glaucomatous patients are characterized by significantly higher impairment of contrast sensitivity, with respect to normal aging (McKendrick et al., 2007). On this basis, it is assumable that glaucoma could alter cognitive performance, especially in advanced stages (McCoskey et al., 2018; Mullany et al., 2021). This is the reason

TABLE 2 | Clinical trials dedicated on neuroprotection in glaucoma (from https://clinicaltrials.gov/).

\begin{tabular}{|c|c|c|c|c|c|}
\hline \multicolumn{6}{|c|}{ Clinical trials dedicated on neuroprotection in glaucoma } \\
\hline Number & Study Title & Identifier & Drug/Approach & Target & Status \\
\hline 1 & $\begin{array}{l}\text { A Randomized, Sham Controlled, Masked Phase II } \\
\text { Study to Evaluate the Safety and Efficacy of Intravitreal } \\
\text { Implantation of NT-501 Encapsulated Cell Therapy for } \\
\text { the Treatment of Glaucoma }\end{array}$ & NCT02862938 & $\begin{array}{l}\text { NT-501 } \\
\text { encapsulated cell } \\
\text { therapy implant }\end{array}$ & $\begin{array}{l}\text { Production of ciliary } \\
\text { neurotrophic factor }\end{array}$ & Active, not recruitin \\
\hline 2 & $\begin{array}{l}\text { A Prospective Randomized Controlled Trial of } \\
\text { GlaucoCetin vs. Placebo in Glaucoma Patients With } \\
\text { Visual Field Loss. }\end{array}$ & NCT04784234 & GlaucoCetin & Neuroprotection & Recruiting \\
\hline 3 & $\begin{array}{l}\text { A Multicenter, Double-Masked, } 2 \text {-Arm Parallel Group } \\
\text { Study Comparing the Effect of Brimonidine } 0.2 \% \text { vs. } \\
\text { Timolol 0.5\% on Visual Field Stability in Patients With } \\
\text { Low-Pressure Glaucoma }\end{array}$ & NCT00317577 & Brimonidine & Neuroprotection & Completed 2004 \\
\hline 4 & $\begin{array}{l}\text { Topical Brimonidine vs. Argon Laser Trabeculoplasty in } \\
\text { Progressing Human Glaucoma. A Prospective } \\
\text { Randomized Clinical Trial. }\end{array}$ & NCT00466479 & Brimonidine & Neuroprotection & Completed 2007 \\
\hline 5 & $\begin{array}{l}\text { A Phase II Study to Investigate the Safety, Efficacy, and } \\
\text { Pharmacokinetic Profile of Twice-Daily DNB-001 in } \\
\text { Previously Untreated Patients With Elevated Intraocular } \\
\text { Hypertension }\end{array}$ & NCT00683501 & DNB-001 & Ion channel modulator & Completed 2008 \\
\hline 6 & $\begin{array}{l}\text { Impact of Oral Versatile Antioxidants on Glaucoma } \\
\text { Progression:Comparative Early Results }\end{array}$ & NCT01544192 & $\begin{array}{l}\text { Gingko Biloba; } \\
\alpha \text {-tocopherol }\end{array}$ & Neuroprotection & Completed 2012 \\
\hline 7 & $\begin{array}{l}\text { Impact of Oral Versatile Antioxidants on Glaucoma } \\
\text { Progression:Comparative Early Results }\end{array}$ & NCT01544192 & $\begin{array}{l}\text { Gingko Biloba; } \\
\alpha \text {-tocopherol }\end{array}$ & Neuroprotection & Completed 2012 \\
\hline 8 & CNTF Cell Implants For Glaucoma: A Phase I Study & NCT01408472 & $\begin{array}{l}\text { NT-501 } \\
\text { encapsulated cell } \\
\text { therapy implant }\end{array}$ & $\begin{array}{l}\text { Production of ciliary } \\
\text { neurotrophic factor }\end{array}$ & Completed 2014 \\
\hline
\end{tabular}


why future research should be focused on the deep assessment of the pathologic cascades occurring beyond the eye, in order to draw more definite conclusion about the impact of glaucomatous changes on brain high order functions.

Based on what described in this review, the careful assessment of CNS involvement might pave the stone for future diagnostic and therapeutic challenges, guiding clinicians and researchers on a more comprehensive evaluation of the pathophysiology of glaucoma and improvements in the management of visual and non-visual alterations complained by glaucomatous patients.

\section{FUTURE PERSPECTIVES}

The current management of glaucoma is mainly based on IOP-lowering medications and IOP-lowering surgical approaches. Although IOP control is a crucial step for the management of glaucomatous patients, what discussed in the present review opens new perspectives in the fields of diagnostic workup and treatment of glaucoma. The awareness regarding the extensive involvement of the CNS, causing the onset of several non-ocular dysfunctions, offers the basis for the development of new treatment strategies dedicated on neuroprotection. Since glutamate-induced excitotoxicity is a main factor associated with glaucomatous neurodegeneration, a possible therapeutic approach might be based on the employment of glutamate inhibitors, such as dizocilpine maleate, memantine and Bis(7)-tacrine (Lipton, 2003; Guo et al., 2006; Fang et al., 2010). These N-methyl D-aspartate (NMDA) receptor blockers act as potent inhibitors of glutamate, although the level of evidence regarding their positive effect in glaucoma setting is not still high and sometimes these molecules resulted toxic for neurons. Furthermore, the administration of memantine was not associated with statistically significant lowering of glaucoma progression. Another class of molecules currently under investigation is represented by ginkgo biloba extracts. Ginkgo biloba already showed positive effects against cognitive impairment in neurodegenerative diseases, such as $\mathrm{AD}$, and positive findings have been reported in glaucoma, thus suggesting a therapeutic role for glaucomatous patients (Quaranta et al., 2003). Brimonidine is a selective alpha-2 receptor adrenergic agonist binding receptors localized within the retina and increasing retinal metabolism and neuronal growth. The rationale regarding the use of brimonidine in glaucoma is based on the neuroprotective role that this molecule should have for retinal ganglion cells, thus preventing their degeneration (Kalapesi et al., 2005). Other therapeutic perspectives are based on the employment of antioxidants, vasoprotective agents, other anti-neurotoxic molecules, such as nitric oxide synthase inhibitors and calciumchannel blockers, other neurotrophic factors, such as BDNF

\section{REFERENCES}

Abu-Amero, K. K., Morales, J., and Bosley, T. M. (2006). Mitochondrial abnormalities in patients with primary open-angle glaucoma. Invest. Ophthalmol. Vis. Sci. 47, 2533-2541. doi: 10.1167/iovs.05-1639 and ciliary neurotrophic factor, and stem cells approaches (Doozandeh and Yazdani, 2016). The main clinical trials dedicated on neuroprotective therapeutic approaches in glaucoma setting are listed in Table 2 . It is worth of notice that two interventional studies are currently active, focused on NT-501 encapsulated cell therapy implant for increasing the production of ciliary neurotrophic factor (NCT02862938) and on testing GlaucoCetin nutraceutical approach (NCT04784234), respectively. With respect to clinical trials focused on cognitive impairment in glaucoma, few studies are currently registered on https://clinicaltrials.gov/. NCT01303939 is a MRI-based clinical trial started in 2011 and ended in 2013 adopting neuroimaging approaches to assess CNS involvement in glaucoma. NCT03333096 is a trial started in 2017, focused on drive fitness and cognitive performance including attention assessments in patients affected by glaucoma and MCI by means of specific neuropsychological tests. NCT03318549 is a clinical trial started in 2017 with the aim of administering visual tasks performance tests to assess visual functional impairment in different eye disorders, including glaucoma.

\section{CONCLUSION}

This review tried to collect the main findings supporting the existence of many elements in common between neurocognitive dysfunctions in glaucoma and neurodegenerative diseases, leading to $\mathrm{MCI} /$ dementia. The eye and the CNS are closely interconnected, placing the basis for the onset of visual symptoms in neurodegenerative diseases and, conversely, of neurocognitive dysfunctions in ophthalmic disorders. Glaucomatous patients are characterized by a wide range of still poorly investigated cognitive dysfunctions. These alterations, governed by neuroinflammatory and neurodegenerative mechanisms, may have a strong impact on patients' quality of life and may remarkably interfere with the proper diagnostic and therapeutic management of glaucoma. Although still representing a novel research field, the vision of glaucoma as a complex neurodegenerative disease would open new diagnostic and therapeutic routes, more focused on the involvement of the neuroretinal and the CNS structures. Further studies should be focused on a deeper assessment of CNS alterations in glaucoma and on the development of new neuroprotective therapeutic strategies.

\section{AUTHOR CONTRIBUTIONS}

AA and EA: review design, data analysis, data interpretation, and manuscript draft. AS, DA, and FF: data acquisition and data analysis. MB and FB: data interpretation, manuscript revision, and study supervision. All authors contributed to the article and approved the submitted version.

Armstrong, R. A. (2008). Visual signs and symptoms of Parkinson's disease. Clin. Exp. Optom. 91, 129-138. doi: 10.1111/j.1444-0938.2007. 00211.x

Armstrong, R. A. (2011). Visual symptoms in Parkinson's disease. Parkinsons Dis. 2011:908306. doi: 10.4061/2011/908306 
Arrigo, A., Calamuneri, A., Milardi, D., Mormina, E., Rania, L., Postorino, E., et al. (2017a). Visual system involvement in patients with newly diagnosed Parkinson disease. Radiology 285, 885-895. doi: 10.1148/radiol.2017161732

Arrigo, A., Calamuneri, A., Mormina, E., Aragona, P., Gaeta, M., and Quartarone, A. (2017b). MRI findings of visual system alterations in Parkinson's disease. Brain 140:e69. doi: 10.1093/brain/ awx 244

Arrigo, A., Rania, L., Calamuneri, A., Postorino, E. I., Mormina, E., Gaeta, M., et al. (2018). Early corneal innervation and trigeminal alterations in Parkinson disease: a pilot study. Cornea 37, 448-454. doi: 10.1097/ICO. 0000000000001517

Ascaso, F. J., Cruz, N., Modrego, P. J., Lopez-Anton, R., Santabárbara, J., Pascual, L. F., et al. (2014). Retinal alterations in mild cognitive impairment and Alzheimer's disease: an optical coherence tomography study. J. Neurol. 261, 1522-1530. doi: 10.1007/s00415-014-7374-Z

Bassuk, S. S., Glass, T. A., and Berkman, L. F. (1999). Social disengagement and incident cognitive decline in community-dwelling elderly persons. Ann. Intern. Med. 131, 165-173. doi: 10.7326/0003-4819-131-3-199908030-00002

Baudouin, C., Kolko, M., Melik-Parsadaniantz, S., and Messmer, E. M. (2021). Inflammation in glaucoma: from the back to the front of the eye and beyond. Prog. Retin. Eye Res. 83:100916. doi: 10.1016/j.preteyeres.2020.100916

Berdahl, J. P., Allingham, R. R., and Johnson, D. H. (2008a). Cerebrospinal fluid pressure is decreased in primary open-angle glaucoma. Ophthalmology 115, 763-768. doi: 10.1016/j.ophtha.2008.01.013

Berdahl, J. P., Fautsch, M. P., Stinnett, S. S., and Allingham, R. R. (2008b). Intracranial pressure in primary open angle glaucoma, normal tension glaucoma and ocular hypertension: a case-control study. Invest. Ophthalmol. Vis. Sci. 49, 5412-5418. doi: 10.1167/iovs.08-2228

Biscetti, L., Lupidi, M., Luchetti, E., Eusebi, P., Gujar, R., Vergaro, A., et al. (2021). Novel noninvasive biomarkers of prodromal Alzheimer disease: The role of optical coherence tomography and optical coherence tomographyangiography. Eur. J. Neurol. 28, 2185-2191. doi: 10.1111/ene.14871

Blanks, J. C., Schmidt, S. Y., Torigoe, Y., Porrello, K. V., Hinton, D. R., and Blanks, R. H. (1996a). Retinal pathology in Alzheimer's disease. II. Regional neuron loss and glial changes in GCL. Neurobiol. Aging. 17, 385-395. doi: 10.1016/0197-4580(96)00009-7

Blanks, J. C., Torigoe, Y., Hinton, D. R., and Blanks, R. H. (1996b). Retinal pathology in Alzheimer's disease. I. Ganglion cell loss in foveal/parafoveal retina. Neurobiol. Aging 17, 377-384. doi: 10.1016/0197-4580(96)00010-3

Bojikian, K. D., Chen, P. P., and Wen, J. C. (2019). Optical coherence tomography angiography in glaucoma. Curr. Opin. Ophthalmol. 30, 110-116. doi: 10.1097/ICU.0000000000000554

Cerquera-Jaramillo, M. A., Nava-Mesa, M. O., González-Reyes, R. E., TellezConti, C., and de-la-Torre, A. (2018). Visual features in Alzheimer's disease: from basic mechanisms to clinical overview. Neural Plast. 2018:2941783. doi: 10.1155/2018/2941783

Chauhan, B. C., Malik, R., Shuba, L. M., Rafuse, P. E., Nicolela, M. T., and Artes, P. H. (2014). Rates of glaucomatous visual field change in a large clinical population. Invest. Ophthalmol. Vis. Sci. 55, 4135-4143. doi: 10.1167/iovs.1414643

Chong, R. S., and Martin, K. R. (2015). Glial cell interactions and glaucoma. Curr. Opin. Ophthalmol. 26, 73-77. doi: 10.1097/ICU.0000000000000125

Chrysostomou, V., Rezania, F., Trounce, I. A., and Crowston, J. G. (2013). Oxidative stress and mitochondrial dysfunction in glaucoma. Curr. Opin. Pharmacol. 13, 12-15. doi: 10.1016/j.coph.2012.09.008

Collaborative Normal-Tension Glaucoma Study Group. (1998). The effectiveness of intraocular pressure reduction in the treatment of normal-tension glaucoma. Am. J. Ophthalmol. 126, 498-505. doi: 10.1016/s0002-9394(98) $00272-4$

Colligris, P., Perez de Lara, M. J., Colligris, B., and Pintor, J. (2018). Ocular manifestations of Alzheimer's and other neurodegenerative diseases: the prospect of the eye as a tool for the early diagnosis of Alzheimer's disease. J. Ophthalmol. 2018:8538573. doi: 10.1155/2018/8538573

Coppola, G., Di Renzo, A., Ziccardi, L., Martelli, F., Fadda, A., Manni, G., et al. (2015). Optical coherence tomography in Alzheimer's disease: a meta-analysis. PLoS One 10:e0134750. doi: 10.1371/journal.pone.0134750

Cuerca, N. (2019). The retina as a biomarker of Parkinson disease. Invest. Ophthalmol. Vis. Sci 60:8.
Cumurcu, T., Sahin, S., and Aydin, E. (2006). Serum homocysteine, vitamin B 12 and folic acid levels in different types of glaucoma. BMC Ophthalmol. 6:6. doi: 10.1186/1471-2415-6-6

Diniz-Filho, A., Delano-Wood, L., Daga, F. B., Cronemberger, S., and Medeiros, F. A. (2017). Association between neurocognitive decline and visual field variability in glaucoma. JAMA Ophthalmol. 135, 734-739. doi: 10.1001/jamaophthalmol.2017.1279

Doozandeh, A., and Yazdani, S. (2016). Neuroprotection in Glaucoma. J. Ophthalmic Vis. Res. 11, 209-220. doi: 10.4103/2008-322X.183923

Dreyer, E. B., Zurakowski, D., Schumer, R. A., Podos, S. M., and Lipton, S. A. (1996). Elevated glutamate levels in the vitreous body of humans and monkeys with glaucoma. Arch. Ophthalmol. 114, 299-305. doi: 10.1001/archopht.1996. 01100130295012

El-Rafei, A., Engelhorn, T., Wärntges, S., Dörfler, A., Hornegger, J., and Michelson, G. (2013). Glaucoma classification based on visual pathway analysis using diffusion tensor imaging. Magn. Reson. Imaging 31, 1081-1091. doi: 10.1016/j.mri.2013.01.001

European Glaucoma Prevention Study (EGPS) Group, Miglior, S., Pfeiffer, N., Torri, V., Zeyen, T., Cunha-Vaz, J., et al. (2007). Predictive factors for open-angle glaucoma among patients with ocular hypertension in the European Glaucoma Prevention Study. Ophthalmology 114, 3-9. doi: 10.1016/j. ophtha.2006.05.075

Fang, J. H., Wang, X. H., Xu, Z. R., and Jiang, F. G. (2010). Neuroprotective effects of bis (7)-tacrine against glutamate-induced retinal ganglion cells damage. BMC Neurosci. 11:31. doi: 10.1186/1471-2202-11-31

Ferreira, S., Pereira, A. C., Quendera, B., Reis, A., Silva, E. D., and CasteloBranco, M. (2016). Primary visual cortical remapping in patients with inherited peripheral retinal degeneration. Neuroimage Clin. 13, 428-438. doi: 10.1016/j. nicl.2016.12.013

Flammer, J. (1994). The vascular concept of glaucoma. Surv. Ophthalmol. 38, S3-S6. doi: 10.1016/0039-6257(94)90041-8

Flammer, J., Orgül, S., Costa, V. P., Orzalesi, N., Krieglstein, G. K., Serra, L. M., et al. (2002). The impact of ocular blood flow in glaucoma. Prog. Retin Eye Res. 21, 359-393. doi: 10.1016/s1350-9462(02)00008-3

Frezzotti, P., Giorgio, A., Motolese, I., De Leucio, A., Iester, M., Motolese, E., et al. (2014). Structural and functional brain changes beyond visual system in patients with advanced glaucoma. PLoS One 9:e105931. doi: 10.1371/journal. pone. 0105931

Frezzotti, P., Giorgio, A., Toto, F., De Leucio, A., and De Stefano, N. (2016). Early changes of brain connectivity in primary open angle glaucoma. Hum. Brain Mapp. 37, 4581-4596. doi: 10.1002/hbm.23330

Garaci, F. G., Bolacchi, F., Cerulli, A., Melis, M., Spanò, A., Cedrone, C., et al. (2009). Optic nerve and optic radiation neurodegeneration in patients with glaucoma: in vivo analysis with 3-T diffusion-tensor MR imaging. Radiology 252, 496-501. doi: 10.1148/radiol.2522081240

Garbutt, S., Matlin, A., Hellmuth, J., Schenk, A. K., Johnson, J. K., Rosen, H., et al. (2008). Oculomotor function in frontotemporal lobar degeneration, related disorders and Alzheimer's disease. Brain 131, 1268-1281. doi: 10.1093/brain/awn047

Gherghel, D., Griffiths, H. R., Hilton, E. J., Cunliffe, I. A., and Hosking, S. L. (2005). Systemic reduction in glutathione levels occurs in patients with primary open-angle glaucoma. Invest. Ophthalmol. Vis. Sci. 46, 877-883. doi: 10.1167/iovs.04-0777

Gilmore, G. C., Groth, K. E., and Thomas, C. W. (2006). Stimulus contrast and word reading speed in Alzheimer's disease. Exp. Aging Res. 31, 15-33. doi: 10.1080/03610730590882828

Giorgio, A., Zhang, J., Costantino, F., De Stefano, N., and Frezzotti, P. (2018). Diffuse brain damage in normal tension glaucoma. Hum. Brain Mapp. 39, 532-541. doi: $10.1002 / \mathrm{hbm} .23862$

Giorgio, A., Zhang, J., Costantino, F., De Stefano, N., and Frezzotti, P. (2020). Altered large-scale brain functional connectivity in ocular hypertension. Front. Neurosci. 14:146. doi: 10.3389/fnins.2020.00146

Glass, J. M. (2007). Visual function and cognitive aging: differential role of contrast sensitivity in verbal versus spatial tasks. Psychol. Aging 22, 233-238. doi: 10.1037/0882-7974.22.2.233

Gordon, M. O., Beiser, J. A., Brandt, J. D., Heuer, D. K., Higginbotham, E. J., Johnson, C. A., et al. (2002). The ocular hypertension treatment study: baseline factors that predict the onset of primary open-angle 
glaucoma. Arch. Ophthalmol. 120, 714-720. doi: 10.1001/archopht.120. 6.714

Grieshaber, M. C., and Flammer, J. (2005). Blood flow in glaucoma. Curr. Opin. Ophthalmol. 16, 79-83. doi: 10.1097/01.icu.0000156134.38495.0b

Grieshaber, M. C., and Flammer, J. (2007). Does the blood-brain barrier play a role in Glaucoma? Surv. Ophthalmol. 52, S115-S121. doi: 10.1016/j.survophthal. 2007.08.005

Grus, F. H., Joachim, S. C., Bruns, K., Lackner, K. J., Pfeiffer, N., and Wax, M. B. (2006). Serum autoantibodies to alpha-fodrin are present in glaucoma patients from Germany and the United States. Invest. Ophthalmol. Vis. Sci. 47, 968-976. doi: 10.1167/iovs.05-0685

Guo, L., Normando, E. M., Shah, P. A., De Groef, L., and Cordeiro, M. F. (2018). Oculo-visual abnormalities in Parkinson's disease: possible value as biomarkers. Mov. Disord. 33, 1390-1406. doi: 10.1002/mds.27454

Guo, L., Salt, T. E., Maass, A., Luong, V., Moss, S. E., Fitzke, F. W., et al. (2006). Assessment of neuroprotective effects of glutamate modulation on glaucomarelated retinal ganglion cell apoptosis in vivo. Invest. Ophthalmol. Vis. Sci. 47, 626-633. doi: 10.1167/iovs.05-0754

Harrabi, H., Kergoat, M. J., Rousseau, J., Boisjoly, H., Schmaltz, H., Moghadaszadeh, S., et al. (2015). Age-related eye disease and cognitive function. Invest. Ophthalmol. Vis. Sci. 56, 1217-1221. doi: 10.1167/iovs. 14-15370

Harris, A., Zarfati, D., Zalish, M., Biller, J., Sheets, C. W., Rechtman, E., et al. (2003). Reduced cerebrovascular blood flow velocities and vasoreactivity in open-angle glaucoma. Am. J. Ophthalmol. 135, 144-147. doi: 10.1016/s00029394(02)01927-x

Hayreh, S. S. (1985). Inter-individual variation in blood supply of the optic nerve head. Its importance in various ischemic disorders of the optic nerve head and glaucoma, low-tension glaucoma and allied disorders. Doc. Ophthalmol. 59, 217-246. doi: 10.1007/BF00159262

Heijl, A., Leske, M. C., Bengtsson, B., Hyman, L., Bengtsson, B., Hussein, M., et al. (2002). Reduction of intraocular pressure and glaucoma progression: results from the early manifest glaucoma trial. Arch. Ophthalmol. 120, 1268-1279. doi: 10.1001/archopht.120.10.1268

Heringa, S. M., Bouvy, W. H., van den Berg, E., Moll, A. C., Kappelle, L. J., and Biessels, G. J. (2013). Associations between retinal microvascular changes and dementia, cognitive functioning and brain imaging abnormalities: a systematic review. J. Cereb. Blood Flow Metab. 33, 983-995. doi: 10.1038/jcbfm. 2013.58

Hernowo, A. T., Prins, D., Baseler, H. A., Plank, T., Gouws, A. D., Hooymans, J. M., et al. (2014). Morphometric analyses of the visual pathways in macular degeneration. Cortex 56, 99-110. doi: 10.1016/j.cortex.2013.01.003

Hinton, D. R., Sadun, A. A., Blanks, J. C., and Miller, C. A. (1986). Opticnerve degeneration in Alzheimer's disease. N. Engl. J. Med. 315, 485-487. doi: 10.1056/NEJM198608213150804

Hofman, P., Hoyng, P., vanderWerf, F., Vrensen, G. F., and Schlingemann, R. O. (2001). Lack of blood-brain barrier properties in microvessels of the prelaminar optic nerve head. Invest. Ophthalmol. Vis. Sci. 42, 895-901.

Honjo, M., Numaga, J., Hara, T., and Asaoka, R. (2017). The association between structure-function relationships and cognitive impairment in elderly glaucoma patients. Sci. Rep. 7:7095. doi: 10.1038/s41598-017-07714-7

Iseri, P. K., Altinaş, O., Tokay, T., and Yüksel, N. (2006). Relationship between cognitive impairment and retinal morphological and visual functional abnormalities in Alzheimer disease. J. Neuroophthalmol. 26, 18-24. doi: 10.1097/01.wno.0000204645.56873.26

Jammal, A. A., Thompson, A. C., Mariottoni, E. B., Urata, C. N., Estrela, T., Berchuck, S. I., et al. (2021). Rates of glaucomatous structural and functional change from a large clinical population: the duke glaucoma registry study. Am. J. Ophthalmol. 222, 238-247. doi: 10.1016/j.ajo.2020.05.019

Jessen, N. A., Munk, A. S., Lundgaard, I., and Nedergaard, M. (2015). The glymphatic system: a beginner's guide. Neurochem. Res. 40, 2583-2599. doi: 10.1007/s11064-015-1581-6

Jiang, S., Kametani, M., and Chen, D. F. (2020). Adaptive immunity: new aspects of pathogenesis underlying neurodegeneration in glaucoma and optic neuropathy. Front. Immunol. 11:65. doi: 10.3389/fimmu.2020.00065

Jiang, M. M., Zhou, Q., Liu, X. Y., Shi, C. Z., Chen, J., and Huang, X. H. (2017). Structural and functional brain changes in early- and mid-stage primary open-angle glaucoma using voxel-based morphometry and functional magnetic resonance imaging. Medicine (Baltimore) 96:e6139. doi: 10.1097/MD. 0000000000006139

Jindal, V. (2015). Interconnection between brain and retinal neurodegenerations. Mol. Neurobiol. 51, 885-892. doi: 10.1007/s12035-014-8733-6

Jonas, J. B. (2011). Role of cerebrospinal fluid pressure in the pathogenesis of glaucoma. Acta Ophthalmol. 89, 505-514. doi: 10.1111/j.1755-3768.2010. 01915.x

Jones-Odeh, E., and Hammond, C. J. (2015). How strong is the relationship between glaucoma, the retinal nerve fibre layer and neurodegenerative diseases such as Alzheimer's disease and multiple sclerosis? Eye (Lond) 29, 1270-1284. doi: 10.1038/eye.2015.158

Jongsiriyanyong, S., and Limpawattana, P. (2018). Mild cognitive impairment in clinical practice: a review article. Am. J. Alzheimers Dis. Other Demen. 33, 500-507. doi: 10.1177/1533317518791401

Ju, W. K., Kim, K. Y., Angert, M., Duong-Polk, K. X., Lindsey, J. D., Ellisman, M. H., et al. (2009). Memantine blocks mitochondrial OPA1 and cytochrome $c$ release and subsequent apoptotic cell death in glaucomatous retina. Invest. Ophthalmol. Vis. Sci. 50, 707-716. doi: 10.1167/iovs.08-2499

Ju, W. K., Liu, Q., Kim, K. Y., Crowston, J. G., Lindsey, J. D., Agarwal, N., et al. (2007). Elevated hydrostatic pressure triggers mitochondrial fission and decreases cellular ATP in differentiated RGC-5 cells. Invest. Ophthalmol. Vis. Sci. 48, 2145-2151. doi: 10.1167/iovs.06-0573

Kalapesi, F. B., Coroneo, M. T., and Hill, M. A. (2005). Human ganglion cells express the alpha-2 adrenergic receptor: relevance to neuroprotection. $\mathrm{Br}$. J. Ophthalmol. 89, 758-763. doi: 10.1136/bjo.2004.053025

Kasi, A., Faiq, M. A., and Chan, K. C. (2019). in vivo imaging of structural, metabolic and functional brain changes in glaucoma. Neural Regen. Res. 14, 446-449. doi: 10.4103/1673-5374.243712

Kavcic, V., Vaughn, W., and Duffy, C. J. (2011). Distinct visual motion processing impairments in aging and Alzheimer's disease. Vis. Res. 51, 386-395. doi: 10.1016/j.visres.2010.12.004

Kim, K. E., and Park, K. H. (2016). Update on the prevalence, etiology, diagnosis and monitoring of normal-tension glaucoma. Asia Pac. J. Ophthalmol. (Phila.) 5, 23-31. doi: 10.1097/APO.0000000000000177

Kirwan, J. F., Hustler, A., Bobat, H., Toms, L., Crabb, D. P., and McNaught, A. I. (2014). Portsmouth visual field database: an audit of glaucoma progression. Eye (Lond) 28, 974-979. doi: 10.1038/eye.2013.294

Koronyo, Y., Salumbides, B. C., Black, K. L., and Koronyo-Hamaoui, M. (2012). Alzheimer's disease in the retina: imaging retinal $A \beta$ plaques for early diagnosis and therapy assessment. Neurodegener. Dis. 10, 285-293. doi: $10.1159 / 000335154$

Kumar, D. K., Choi, S. H., Washicosky, K. J., Eimer, W. A., Tucker, S., Ghofrani, J., et al. (2016). Amyloid- $\beta$ peptide protects against microbial infection in mouse and worm models of Alzheimer's disease. Sci. Transl. Med. 8:340ra72. doi: 10.1126/scitranslmed.aaf1059

Kumar, S., Malik, M. A., Goswami, S., Sihota, R., and Kaur, J. (2016). Candidate genes involved in the susceptibility of primary open angle glaucoma. Gene 577, 119-131. doi: 10.1016/j.gene.2015.11.032

Kumar, S., Malik, M. A., K, S., Sihota, R., and Kaur, J. (2017). Genetic variants associated with primary open angle glaucoma in Indian population. Genomics 109, 27-35. doi: 10.1016/j.ygeno.2016.11.003

Lakshminarayanan, V., Lagrave, J., Kean, M. L., Dick, M., and Shankle, R. (1996). Vision in dementia: contrast effects. Neurol. Res. 18, 9-15. doi: 10.1080/01616412.1996.11740369

Langenegger, S. J., Funk, J., and Töteberg-Harms, M. (2011). Reproducibility of retinal nerve fiber layer thickness measurements using the eye tracker and the retest function of Spectralis SD-OCT in glaucomatous and healthy control eyes. Invest. Ophthalmol. Vis. Sci. 52, 3338-3344. doi: 10.1167/iovs. $10-6611$

Lee, S. H., Han, J. W., Lee, E. J., Kim, T. W., Kim, H., and Kim, K. W. (2020). Cognitive impairment and lamina cribrosa thickness in primary open-angle glaucoma. Transl. Vis. Sci. Technol. 9:17. doi: 10.1167/tvst.9.7.17

Lee, E. J., Lee, K. M., Lee, S. H., and Kim, T. W. (2016). OCT Angiography of the peripapillary retina in primary open-angle glaucoma. Invest. Ophthalmol. Vis. Sci. 57, 6265-6270. doi: 10.1167/iovs.16-20287

Lee, Y. T., and Pai, M. C. (2012). Recognition of personality familiar scenes in patients with very mild Alzheimer's disease: effects of spatial frequency and luminance. J. Alzheimers Dis. 29, 441-448. doi: 10.3233/JAD-2011-111601 
Leske, M. C., Wu, S. Y., Hyman, L., Nemesure, B., Hennis, A., Schachat, A. P., et al. (2004). Four-year incidence of visual impairment: barbados incidence study of eye diseases. Ophthalmology 111, 118-124. doi: 10.1016/j.ophtha.2003. 04.002

Lešták, J., Tintera, J., Karel, I., Svatá, Z., and Rozsíval, P. (2013). Functional magnetic resonance imaging in patients with the wet form of age-related macular degeneration. Neuroophthalmology 37, 192-197. doi: 10.3109/01658107.2013.819581

Leung, C. K., Cheung, C. Y., Weinreb, R. N., Qiu, K., Liu, S., Li, H., et al. (2010). Evaluation of retinal nerve fiber layer progression in glaucoma: a study on optical coherence tomography guided progression analysis. Invest. Ophthalmol. Vis. Sci. 51, 217-222. doi: 10.1167/iovs.09-3468

Li, C., Cai, P., Shi, L., Lin, Y., Zhang, J., Liu, S., et al. (2012). Voxel-based morphometry of the visual-related cortex in primary open angle glaucoma. Curr. Eye Res. 37, 794-802. doi: 10.3109/02713683.2012.683506

Li, F., Lin, F., Gao, K., Cheng, W., Song, Y., Liu, Y., et al. (2021). Association of foveal avascular zone area withstructural and functional progression in glaucoma patients. Br. J. Ophthalmol. [Online ahead of print]. doi: 10.1136/bjophthalmol-2020-318065

Li, T., Qu, X., Chen, W., Wang, Q., Wang, H., Wang, Y., et al. (2020). Altered information flow and microstructure abnormalities of visual cortex in normaltension glaucoma: evidence from resting-state fMRI and DKI. Brain Res. 1741:146874. doi: 10.1016/j.brainres.2020.146874

Lim, J. K., Li, Q. X., He, Z., Vingrys, A. J., Wong, V. H., Currier, N., et al. (2016). The eye as a biomarker for Alzheimer's disease. Front. Neurosci. 10:536. doi: $10.3389 /$ fnins.2016.00536

Lipton, S. A. (2003). Possible role for memantine in protecting retinal ganglion cells from glaucomatous damage. Surv. Ophthalmol. 48, S38-S46. doi: 10.1016/s0039-6257(03)00008-0

Liu, D., Zhang, L., Li, Z., Zhang, X., Wu, Y., Yang, H., et al. (2015). Thinner changes of the retinal nerve fiber layer in patients with mild cognitive impairment and Alzheimer's disease. BMC Neurol. 15:14. doi: 10.1186/s12883-015-0268-6

López-Riquelme, N., Villalba, C., Tormo, C., Belmonte, A., Fernandez, C., Torralba, G., et al. (2015). Endothelin-1 levels and biomarkers of oxidative stress in glaucoma patients. Int. Ophthalmol. 35, 527-532. doi: 10.1007/s10792014-9979-8

Mallick, J., Devi, L., Malik, P. K., and Mallick, J. (2016). Update on normal tension glaucoma. J. Ophthalmic Vis. Res. 11, 204-208. doi: 10.4103/2008-322X. 183914

Maurano, S. T. P., da Silva, D. J., Ávila, M. P., and Magacho, L. (2018). Cognitive evaluation of patients with glaucoma and its comparison with individuals with Alzheimer's disease. Int. Ophthalmol. 38, 1839-1844. doi: 10.1007/s10792-0170658-4

McCoskey, M., Addis, V., Goodyear, K., Sankar, P. S., Ying, G. S., Yu, Y., et al. (2018). Association between primary open-angle glaucoma and cognitive impairment as measured by the montreal cognitive assessment. Neurodegener. Dis. 18, 315-322. doi: 10.1159/000496233

McKendrick, A. M., Sampson, G. P., Walland, M. J., and Badcock, D. R. (2007). Contrast sensitivity changes due to glaucoma and normal aging: low-spatial-frequency losses in both magnocellular and parvocellular pathways. Invest. Ophthalmol. Vis. Sci. 48, 2115-2122. doi: 10.1167/iovs. 06-1208

McKinnon, S. J. (2012). The cell and molecular biology of glaucoma: common neurodegenerative pathways and relevance to glaucoma. Invest. Ophthalmol. Vis. Sci. 53, 2485-2487. doi: 10.1167/iovs.12-9483j

McKinnon, S. J., Lehman, D. M., Kerrigan-Baumrind, L. A., Merges, C. A., Pease, M. E., Kerrigan, D. F., et al. (2002). Caspase activation and amyloid precursor protein cleavage in rat ocular hypertension. Invest. Ophthalmol. Vis. Sci. 43, 1077-1087.

Moore, D., Harris, A., Wudunn, D., Kheradiya, N., and Siesky, B. (2008). Dysfunctional regulation of ocular blood flow: a risk factor for glaucoma? Clin. Ophthalmol. 2, 849-861. doi: 10.2147/opth.s2774

Morgan, W. H., Chauhan, B. C., Yu, D. Y., Cringle, S. J., Alder, V. A., and House, P. H. (2002). Optic disc movement with variations in intraocular and cerebrospinal fluid pressure. Invest. Ophthalmol. Vis. Sci. 43, 3236-3242.

Morgan, W. H., Yu, D. Y., Alder, V. A., Cringle, S. J., Cooper, R. L., House, P. H., et al. (1998). The correlation between cerebrospinal fluid pressure and retrolaminar tissue pressure. Invest. Ophthalmol. Vis. Sci. 39, 1419-1428.
Morgan, W. H., Yu, D. Y., Cooper, R. L., Alder, V. A., Cringle, S. J., and Constable, I. J. (1995). The influence of cerebrospinal fluid pressure on the lamina cribrosa tissue pressure gradient. Invest. Ophthalmol. Vis. Sci. 36, $1163-1172$.

Mozaffarieh, M., and Flammer, J. (2013). New insights in the pathogenesis and treatment of normal tension glaucoma. Curr. Opin. Pharmacol. 13, 43-49. doi: 10.1016/j.coph.2012.10.001

Mullany, S., Xiao, L., Qassim, A., Marshall, H., Gharahkhani, P., MacGregor, S., et al. (2021). Normal-tension glaucoma is associated with cognitive impairment. Br. J. Ophthalmol. [Online ahead of print]. doi: 10.1136/bjophthalmol-2020-317461

Munemasa, Y., and Kitaoka, Y. (2013). Molecular mechanisms of retinal ganglion cell degeneration in glaucoma and future prospects for cell body and axonal protection. Front. Cell. Neurosci. 6:60. doi: 10.3389/fncel.2012.00060

Naaman, E., Ya'ari, S., Itzkovich, C., Safuri, S., Macsi, F., Kellerman, L., et al. (2020). The retinal toxicity profile towards assemblies of Amyloid- $\beta$ indicate the predominant pathophysiological activity of oligomeric species. Sci. Rep. 10:20954. doi: 10.1038/s41598-020-77712-9

Ning, A., Cui, J., To, E., Ashe, K. H., and Matsubara, J. (2008). Amyloid-beta deposits lead to retinal degeneration in a mouse model of Alzheimer disease. Invest. Ophthalmol. Vis. Sci. 49, 5136-5143. doi: 10.1167/iovs.08-1849

Nuzzi, R., Dallorto, L., and Rolle, T. (2018). Changes of visual pathway and brain connectivity in glaucoma: a systematic review. Front. Neurosci. 12:363. doi: $10.3389 /$ fnins.2018.00363

Nuzzi, R., Dallorto, L., and Vitale, A. (2020). Cerebral modifications and visual pathway reorganization in maculopathy: a systematic review. Front. Neurosci. 14:755. doi: $10.3389 /$ fnins.2020.00755

Olivo, G., Melillo, P., Cocozza, S., D’Alterio, F. M., Prinster, A., Testa, F., et al. (2015). Cerebral involvement in Stargardt's disease: A VBM and TBSS study. Invest. Ophthalmol. Vis. Sci. 56, 7388-7397. doi: 10.1167/iovs.15-16899

Omodaka, K., Murata, T., Sato, S., Takahashi, M., Tatewaki, Y., Nagasaka, T., et al. (2014). Correlation of magnetic resonance imaging optic nerve parameters to optical coherence tomography and the visual field in glaucoma. Clin. Exp. Ophthalmol. 42, 360-368. doi: 10.1111/ceo.12237

Osborne, N. N., Melena, J., Chidlow, G., and Wood, J. P. (2001). A hypothesis to explain ganglion cell death caused by vascular insults at the optic nerve head: possible implication for the treatment of glaucoma. Br. J. Ophthalmol. 85, 1252-1259. doi: 10.1136/bjo.85.10.1252

Park, B. C., Tibudan, M., Samaraweera, M., Shen, X., and Yue, B. Y. (2007) Interaction between two glaucoma genes, optineurin and myocilin. Genes Cells 12, 969-979. doi: 10.1111/j.1365-2443.2007.01102.x

Pascolini, D., and Mariotti, S. P. (2012). Global estimates of visual impairment: 2010. Br. J. Ophthalmol. 96, 614-618. doi: 10.1136/bjophthalmol-2011-300539

Petersen, R. C. (2011). Clinical practice. Mild cognitive impairment. N. Engl. J. Med. 364, 2227-2234. doi: 10.1056/NEJMcp0910237

Prins, D., Hanekamp, S., and Cornelissen, F. W. (2016). Structural brain MRI studies in eye diseases: are they clinically relevant? A review of current findings. Acta Ophthalmol. 94, 113-121. doi: 10.1111/aos.12825

Quaranta, L., Bettelli, S., Uva, M. G., Semeraro, F., Turano, R., and Gandolfo, E. (2003). Effect of Ginkgo biloba extract on preexisting visual field damage in normal tension glaucoma. Ophthalmology 110, 359-362. doi: 10.1016/S01616420(02)01745-1

Quaranta, L., Bruttini, C., Micheletti, E., Konstas, A. G. P., Michelessi, M., Oddone, F., et al. (2021). Glaucoma and neuroinflammation: an overview. Surv Ophthalmol. 66, 693-713. doi: 10.1016/j.survophthal.2021.02.003

Raman, P., Khy Ching, Y., Sivagurunathan, P. D., Ramli, N., and Mohd Khalid, K. H. (2019). The association between visual field reliability indices and cognitive impairment in glaucoma patients. J. Glaucoma 28, 685-690. doi: $10.1097 /$ IJG.0000000000001269

Rao, V. R., Krishnamoorthy, R. R., and Yorio, T. (2007). Endothelin-1, endothelin $\mathrm{A}$ and $\mathrm{B}$ receptor expression and their pharmacological properties in GFAP negative human lamina cribrosa cells. Exp. Eye Res. 84, 1115-1124. doi: 10.1016/j.exer.2007.02.010

Rao, V. R., Krishnamoorthy, R. R., and Yorio, T. (2008). Endothelin-1 mediated regulation of extracellular matrix collagens in cells of human lamina cribrosa. Exp. Eye Res. 86, 886-894. doi: 10.1016/j.exer.2008.03.003

Rego, A. C., and Oliveira, C. R. (2003). Mitochondrial dysfunction and reactive oxygen species in excitotoxicity and apoptosis: implications for the 
pathogenesis of neurodegenerative diseases. Neurochem. Res. 28, 1563-1574. doi: 10.1023/a:1025682611389

Ren, R., Jonas, J. B., Tian, G., Zhen, Y., Ma, K., Li, S., et al. (2010). Cerebrospinal fluid pressure in glaucoma: a prospective study. Ophthalmology 117, 259-266. doi: 10.1016/j.ophtha.2009.06.058

Ren, R., Wang, N., Zhang, X., Cui, T., and Jonas, J. B. (2011). Trans-lamina cribrosa pressure difference correlated with neuroretinal rim area in glaucoma. Graefes Arch. Clin. Exp. Ophthalmol. 249, 1057-1063. doi: 10.1007/s00417-0111657-1

Reznicek, L., Seidensticker, F., Mann, T., Hübert, I., Buerger, A., Haritoglou, C., et al. (2013). Correlation between peripapillary retinal nerve fiber layer thickness and fundus autofluorescence in primary open-angle glaucoma. Clin. Ophthalmol. 7, 1883-1888. doi: 10.2147/OPTH.S49112

Risacher, S. L., Wudunn, D., Pepin, S. M., MaGee, T. R., McDonald, B. C., Flashman, L. A., et al. (2013). Visual contrast sensitivity in Alzheimer's disease, mild cognitive impairment and older adults with cognitive complaints. Neurobiol. Aging 34, 1133-1144. doi: 10.1016/j.neurobiolaging.2012. 08.007

Rita Machado, A., Carvalho Pereira, A., Ferreira, F., Ferreira, S., Quendera, B., Silva, E., et al. (2017). Structure-function correlations in Retinitis Pigmentosa patients with partially preserved vision: a voxel-based morphometry study. Sci. Rep. 7:11411. doi: 10.1038/s41598-017-11317-7

Rizzo, M., Anderson, S. W., Dawson, J., and Nawrot, M. (2000). Vision and cognition in Alzheimer's disease. Neuropsychologia 38, 1157-1169. doi: 10.1038/s41598-017-11317-7

Romano, C., Barrett, D. A., Li, Z., Pestronk, A., and Wax, M. B. (1995). Antirhodopsin antibodies in sera from patients with normal-pressure glaucoma. Invest. Ophthalmol. Vis. Sci. 36, 1968-1975.

Romano, C., Li, Z., Arendt, A., Hargrave, P. A., and Wax, M. B. (1999). Epitope mapping of anti-rhodopsin antibodies from patients with normal pressure glaucoma. Invest. Ophthalmol. Vis. Sci. 40, 1275-1280.

Rosengarth, K., Keck, I., Brandl-Rühle, S., Frolo, J., Hufendiek, K., Greenlee, M. W., et al. (2013). Functional and structural brain modifications induced by oculomotor training in patients with age-related macular degeneration. Front. Psychol. 4:428. doi: 10.3389/fpsyg.2013.00428

Salt, T. E., and Cordeiro, M. F. (2006). Glutamate excitotoxicity in glaucoma: throwing the baby out with the bathwater? Eye (Lond) 20, 730-731. doi: 10.1038/sj.eye.6701967

Schmitz-Valckenberg, S., Holz, F. G., Bird, A. C., and Spaide, R. F. (2008). Fundus autofluorescence imaging: review and perspectives. Retina 28, 385-409. doi: 10.1097/IAE.0b013e318164a907

Scinto, L. F. M. (2007). ApoE allelic variability influences pupil response to cholinergic challenge and cognitive impairment. Genes Brain Behav. 6, 209-215. doi: 10.1111/j.1601-183X.2006.00247.x

Seitz, R., Ohlmann, A., and Tamm, E. R. (2013). The role of Müller glia and microglia in glaucoma. Cell Tissue Res. 353, 339-345. doi: 10.1007/s00441-0131666-y

Seki, M., Tanaka, T., Sakai, Y., Fukuchi, T., Abe, H., Nawa, H., et al. (2005). Müller cells as a source of brain-derived neurotrophic factor in the retina: noradrenaline upregulates brain-derived neurotrophic factor levels in cultured rat Müller cells. Neurochem. Res. 30, 1163-1170. doi: 10.1007/s11064-0057936-7

Siaudvytyte, L., Januleviciene, I., Daveckaite, A., Ragauskas, A., Bartusis, L., Kucinoviene, J., et al. (2015). Literature review and meta-analysis of translaminar pressure difference in open-angle glaucoma. Eye (Lond) 29, 1242-1250. doi: 10.1038/eye.2015.127

Siaudvytyte, L., Januleviciene, I., Ragauskas, A., Bartusis, L., Meiliuniene, I., Siesky, B., et al. (2014). The difference in translaminar pressure gradient and neuroretinal rim area in glaucoma and healthy subjects. J. Ophthalmol. 2014:937360. doi: 10.1155/2014/937360

Sivak, J. M. (2013). The aging eye: common degenerative mechanisms between the Alzheimer's brain and retinal disease. Invest. Ophthalmol. Vis. Sci. 54, 871-880. doi: 10.1167/iovs.12-10827

Spaide, R. F., Fujimoto, J. G., Waheed, N. K., Sadda, S. R., and Staurenghi, G. (2018). Optical coherence tomography angiography. Prog. Retin Eye Res. 64, $1-55$.

Stasi, K., Nagel, D., Yang, X., Wang, R. F., Ren, L., Podos, S. M., et al. (2006). Complement component $1 \mathrm{Q}(\mathrm{C} 1 \mathrm{Q})$ upregulation in retina of murine, primate and human glaucomatous eyes. Invest. Ophthalmol. Vis. Sci. 47, 1024-1029. doi: $10.1167 /$ iovs.05-0830

Su, C. W., Lin, C. C., Kao, C. H., and Chen, H. Y. (2016). Association between glaucoma and the risk of dementia. Medicine (Baltimore) 95:e2833. doi: 10.1097/MD.0000000000002833

Sung, M. S., Choi, S. M., Kim, J., Ha, J. Y., Kim, B. C., Heo, H., et al. (2019). Inner retinal thinning as a biomarker for cognitive impairment in de novo Parkinson's disease. Sci. Rep. 9:11832. doi: 10.1038/s41598-019-48388-7

Szatkowski, M., and Attwell, D. (1994). Triggering and execution of neuronal death in brain ischaemia: two phases of glutamate release by different mechanisms. Trends Neurosci. 17, 359-365. doi: 10.1016/0166-2236(94) 90040-x

Tamura, H., Kawakami, H., Kanamoto, T., Kato, T., Yokoyama, T., Sasaki, K., et al. (2006). High frequency of open-angle glaucoma in Japanese patients with Alzheimer's disease. J. Neurol. Sci. 246, 79-83. doi: 10.1016/j.jns.2006. 02.009

Tezel, G. (2006). Oxidative stress in glaucomatous neurodegeneration: mechanisms and consequences. Prog. Retin Eye Res. 25, 490-513. doi: 10.1016/j. preteyeres.2006.07.003

Tezel, G. (2008). TNF-alpha signaling in glaucomatous neurodegeneration. Prog. Brain Res. 173, 409-421. doi: 10.1016/S0079-6123(08)01128-X

Tezel, G. (2021). Multifactorial pathogenic processes of retinal ganglion cell degeneration in glaucoma towards multi-target strategies for broader treatment effects. Cells 10:1372. doi: 10.3390/cells10061372

Tezel, G., Edward, D. P., and Wax, M. B. (1999). Serum autoantibodies to optic nerve head glycosaminoglycans in patients with glaucoma. Arch. Ophthalmol. 117, 917-924. doi: 10.1001/archopht.117.7.917

Tezel, G., Seigel, G. M., and Wax, M. B. (1998). Autoantibodies to small heat shock proteins in glaucoma. Invest. Ophthalmol. Vis. Sci. 39, 2277-2287.

Tezel, G., and Wax, M. B. (2000). Increased production of tumor necrosis factoralpha by glial cells exposed to simulated ischemia or elevated hydrostatic pressure induces apoptosis in cocultured retinal ganglion cells. J. Neurosci. 20, 8693-8700. doi: 10.1523/JNEUROSCI.20-23-08693.2000

Tezel, G., and Wax, M. B. (2004). The immune system and glaucoma. Curr. Opin. Ophthalmol. 15, 80-84. doi: 10.1097/00055735-200404000-00003

Tham, Y. C., Li, X., Wong, T. Y., Quigley, H. A., Aung, T., and Cheng, C. Y. (2014). Global prevalence of glaucoma and projections of glaucoma burden through 2040: a systematic review and meta-analysis. Ophthalmology 121, 2081-2090. doi: 10.1016/j.ophtha.2014.05.013

The AGIS Investigators. (2000). The Advanced Glaucoma Intervention Study (AGIS): 7. The relationship between control of intraocular pressure and visual field deterioration. Am. J. Ophthalmol. 130, 429-440. doi: 10.1016/s00029394(00)00538-9

Thomas, D., and Duguid, G. (2004). Optical coherence tomography-a review of the principles and contemporary uses in retinal investigation. Eye (Lond) 18 561-570. doi: 10.1038/sj.eye.6700729

Tong, Y., Wang, T., Zhang, X., He, Y., and Jiang, B. (2021). Optical coherence tomography evaluation of peripapillary and macular structure changes in pre-perimetric glaucoma, early perimetric glaucoma and ocular hypertension: a systematic review and meta-analysis. Front. Med. (Lausanne) 8:696004. doi: 10.3389/fmed.2021.696004

Trick, G. L., Trick, L. R., Morris, P., and Wolf, M. (1995). Visual field loss in senile dementia of the Alzheimer's type. Neurology 45, 68-74.

Turgut, B., Kaya, M., Arslan, S., Demir, T., Güler, M., and Kaya, M. K. (2010). Levels of circulating homocysteine, vitamin B6, vitamin B12 and folate in different types of open-angle glaucoma. Clin. Interv. Aging 5, 133-139. doi: $10.2147 /$ cia.s9918

Türkcü, F. M., Köz, O. G., Yarangümeli, A., Oner, V., and Kural, G. (2013). Plasma homocysteine, folic acid and vitamin $\mathrm{B}_{12}$ levels in patients with pseudoexfoliation syndrome, pseudoexfoliation glaucoma and normotensive glaucoma. Medicina (Kaunas) 49, 214-218.

van de Kreeke, J. A., Nguyen, H. T., Konijnenberg, E., Tomassen, J., den Braber, A., Ten Kate, M., et al. (2020). Optical coherence tomography angiography in preclinical Alzheimer's disease. Br. J. Ophthalmol. 104, 157-161. doi: 10.1136/bjophthalmol-2019-314127

Van Melkebeke, L., Barbosa-Breda, J., Huygens, M., and Stalmans, I. (2018). Optical coherence tomography angiography in glaucoma: a review. Ophthalmic Res. 60, 139-151. doi: 10.1159/000488495 
Varadaraj, V., Munoz, B., Deal, J. A., An, Y., Albert, M. S., Resnick, S. M., et al. (2021). Association of vision impairment with cognitive decline across multiple domains in older adults. JAMA Netw. Open 4:e2117416. doi: 10.1001/jamanetworkopen.2021.17416

Varin, M., Kergoat, M. J., Belleville, S., Li, G., Rousseau, J., Roy-Gagnon, M. H., et al. (2020). Age-related eye disease and cognitive function: the search for mediators. Ophthalmology 127, 660-666. doi: 10.1016/j.ophtha.2019.10.004

Vidal, K. S., Suemoto, C. K., Moreno, A. B., Duncan, B., Schmidt, M. I., Maestri, M., et al. (2020). Association between cognitive performance and self-reported glaucoma in middle-aged and older adults: a cross-sectional analysis of ELSA-Brasil. Braz. J. Med. Biol. Res. 53:e10347. doi: 10.1590/1414431X202010347

Viestenz, A., Langenbucher, A., Laemmer, R., Mardin, C. Y., and Naumann, G. O. H. (2006). Parapapillary fundus autofluorescence is an glaucoma indicator. Invest. Ophthalmol. Vis. Sci 47:3656.

Volkert, M. R., and Crowley, D. J. (2020). Preventing neurodegeneration by controlling oxidative stress: the role of OXR1. Front. Neurosci. 14:611904. doi: $10.3389 /$ fnins.2020.611904

Vrabec, J. P., and Levin, L. A. (2007). The neurobiology of cell death in glaucoma. Eye (Lond) 21, S11-S14. doi: 10.1038/sj.eye.6702880

Vu, D. M., Brahmajothi, M. V., Abou-Donia, M. B., and Tseng, H. (2019). Serum autoantibody biomarkers of neuroinflammation and neurodegeneration in glaucoma. Invest. Ophthalmol. Vis. Sci 60:680. doi: 10.1186/s12974-016$0542-6$

Wang, J., Li, T., Zhou, P., Wang, N., Xian, J., and He, H. (2017). Altered functional connectivity within and between the default model network and the visual network in primary open-angle glaucoma: a resting-state fMRI study. Brain Imaging Behav. 11, 1154-1163. doi: 10.1007/s11682-016-9597-3

Wang, X., Lou, N., Eberhardt, A., Yang, Y., Kusk, P., Xu, Q., et al. (2020). An ocular glymphatic clearance system removes $\beta$-amyloid from the rodent eye. Sci. Transl. Med. 12:eaaw3210. doi: 10.1126/scitranslmed.aaw3210

Wang, L., and Mao, X. (2021). Role of retinal amyloid- $\beta$ in neurodegenerative diseases: overlapping mechanisms and emerging clinical applications. Int. J. Mol. Sci. 22:2360. doi: 10.3390/ijms22052360

Wang, Q., Qu, X., Chen, W., Wang, H., Huang, C., Li, T., et al. (2021). Altered coupling of cerebral blood flow and functional connectivity strength in visual and higher order cognitive cortices in primary open angle glaucoma. J. Cereb. Blood Flow Metab. 41, 901-913. doi: 10.1177/0271678X20935274

Wang, X., Zhao, Q., Tao, R., Lu, H., Xiao, Z., Zheng, L., et al. (2021). Decreased retinal vascular density in Alzheimer's disease $(\mathrm{AD})$ and mild cognitive impairment (MCI): an optical coherence tomography angiography (OCTA) study. Front. Aging Neurosci. 12:572484. doi: 10.3389/fnagi.2020.572484

Wei, X., Cho, K. S., Thee, E. F., Jager, M. J., and Chen, D. F. (2019). Neuroinflammation and microglia in glaucoma: time for a paradigm shift. J. Neurosci. Res. 97, 70-76. doi: 10.1002/jnr.24256

Wensor, M. D., McCarty, C. A., Stanislavsky, Y. L., Livingston, P. M., and Taylor, H. R. (1998). The prevalence of glaucoma in the melbourne visual impairment project. Ophthalmology 105, 733-739. doi: 10.1016/S01616420(98)94031-3

Williams, A. L., Lackey, J., Wizov, S. S., Chia, T. M., Gatla, S., Moster, M. L., et al. (2013). Evidence for widespread structural brain changes in glaucoma: a preliminary voxel-based MRI study. Invest. Ophthalmol. Vis. Sci. 54, 5880-5887. doi: $10.1167 /$ iovs.13-11776

Wilson, R. S., Mendes De Leon, C. F., Barnes, L. L., Schneider, J. A., Bienias, J. L., Evans, D. A., et al. (2002). Participation in cognitively stimulating activities and risk of incident Alzheimer disease. JAMA 287, 742-748. doi: 10.1001/jama.287. 6.742

Wostyn, P., De Groot, V., Van Dam, D., Audenaert, K., Killer, H. E., and De Deyn, P. P. (2016). Age-related macular degeneration, glaucoma and Alzheimer's disease: amyloidogenic diseases with the same glymphatic background? Cell. Mol. Life Sci. 73, 4299-4301. doi: 10.1007/s00018-0162348-1
Wostyn, P., Van Dam, D., Audenaert, K., Killer, H. E., De Deyn, P. P., and De Groot, V. (2015). A new glaucoma hypothesis: a role of glymphatic system dysfunction. Fluids Barriers CNS 12:16. doi: 10.1186/s12987-015 $-0012-\mathrm{z}$

WuDunn, D., Takusagawa, H. L., Sit, A. J., Rosdahl, J. A., Radhakrishnan, S., Hoguet, A., et al. (2021). OCT angiography for the diagnosis of glaucoma: a report by the American academy of ophthalmology. Ophthalmology 128, 1222-1235. doi: 10.1016/j.ophtha.2020.12.027

Xu, X. H., Zou, J. Y., Geng, W., and Wang, A. Y. (2019). Association between glaucoma and the risk of Alzheimer's disease: a systematic review of observational studies. Acta Ophthalmol. 97, 665-671. doi: 10.1111/aos. 14114

Yu, L., Xie, B., Yin, X., Liang, M., Evans, A. C., Wang, J., et al. (2013). Reduced cortical thickness in primary open-angle glaucoma and its relationship to the retinal nerve fiber layer thickness. PLoS One 8:e73208. doi: 10.1371/journal. pone. 0073208

Zhang, S., Wang, B., Xie, Y., Zhu, S., Thomas, R., Qing, G., et al. (2015). Retinotopic changes in the gray matter volume and cerebral blood flow in the primary visual cortex of patients with primary open-angle glaucoma. Invest. Ophthalmol. Vis. Sci. 56, 6171-6178. doi: 10.1167/iovs.15-17286

Zhang, P., Wen, W., Sun, X., and He, S. (2016). Selective reduction of fMRI responses to transient achromatic stimuli in the magnocellular layers of the LGN and the superficial layer of the SC of early glaucoma patients. Hum. Brain Mapp. 37, 558-569. doi: 10.1002/hbm.23049

Zhao, X., Sun, R., Luo, X., Wang, F., and Sun, X. (2021). The interaction between microglia and macroglia in glaucoma. Front. Neurosci. 15:610788. doi: 10.1167/iovs.15-17286

Zhou, W., Muir, E. R., Chalfin, S., Nagi, K. S., and Duong, T. Q. (2017). MRI study of the posterior visual pathways in primary open angle glaucoma. J. Glaucoma 26, 173-181. doi: 10.1097/IJG.0000000000000558

Zikou, A. K., Kitsos, G., Tzarouchi, L. C., Astrakas, L., Alexiou, G. A., and Argyropoulou, M. I. (2012). Voxel-based morphometry and diffusion tensor imaging of the optic pathway in primary open-angle glaucoma: a preliminary study. Am. J. Neuroradiol. 33, 128-134. doi: 10.3174/ajnr. A2714

Conflict of Interest: FB consultant for: Alcon (Fort Worth, Texas, USA) Alimera Sciences (Alpharetta, Georgia, USA), Allergan Inc. (Irvine, California, USA), Farmila-Thea (Clermont-Ferrand, France), Bayer Shering-Pharma (Berlin, Germany), Bausch and Lomb (Rochester, New York, USA), Genentech (San Francisco, California, USA), Hoffmann-La-Roche (Basel, Switzerland), Novagali Pharma (Évry, France), Novartis (Basel, Switzerland), Sanofi-Aventis (Paris, France), Thrombogenics (Heverlee, Belgium), Zeiss (Dublin, California, USA).

The remaining authors declare that the research was conducted in the absence of any commercial or financial relationships that could be construed as a potential conflict of interest.

Publisher's Note: All claims expressed in this article are solely those of the authors and do not necessarily represent those of their affiliated organizations, or those of the publisher, the editors and the reviewers. Any product that may be evaluated in this article, or claim that may be made by its manufacturer, is not guaranteed or endorsed by the publisher.

Copyright (อ 2021 Arrigo, Aragona, Saladino, Arrigo, Fantaguzzi, Battaglia Parodi and Bandello. This is an open-access article distributed under the terms of the Creative Commons Attribution License (CC BY). The use, distribution or reproduction in other forums is permitted, provided the original author(s) and the copyright owner(s) are credited and that the original publication in this journal is cited, in accordance with accepted academic practice. No use, distribution or reproduction is permitted which does not comply with these terms. 